\title{
An Investigation of Secondary School STEM Subjects as Predictors of Academic Performance in Tertiary Level Health Sciences Programs
}

\author{
Conner Blackmore ${ }^{1}$, Kathryn Hird ${ }^{2}$ \& Ryan S Anderton ${ }^{3}$ \\ ${ }^{1}$ School of Medicine, University of Notre Dame Australia, Fremantle, Western Australia, Australia \\ ${ }^{2}$ School of Medicine, University of Notre Dame Australia, Fremantle, Western Australia, Australia \\ ${ }^{3}$ Institute for Health Research and School of Health Sciences, University of Notre Dame Australia, Fremantle, \\ Western Australia, Australia \\ Correspondence: Conner Blackmore, School of Medicine, University of Notre Dame Australia, Fremantle, Western \\ Australia, Australia
}

Received: August 24, 2020

Accepted: September 22, 2020

Online Published: September 23, 2020

doi:10.5430/ijhe.v10n1p76

URL: https://doi.org/10.5430/ijhe.v10n1p76

\begin{abstract}
Tertiary institutions are experiencing an increased number of enrolments, with students varying in their demographics, previous education, and academic achievement. This relative increase in undergraduate enrolments in Australia has not translated to an increase in student retention or graduate numbers. This prompts the need to explore predictors of academic performance for tertiary students to identify those most at risk of underperforming. This study aimed to investigate the relationship between secondary school subject completion and undergraduate grade point average (GPA). A cohort of 709 secondary school students entering undergraduate health science courses between 2012 and 2015 at an Australian university were investigated. Completion of Mathematics 3C3D, Physics, Chemistry and Physical Education Australian Tertiary Admission Rank (ATAR) subjects were significantly associated with GPA. In a subset of 458 students, longitudinal analysis revealed completion of secondary school Mathematics 3C3D was a significant predictor of academic performance over the duration of the tertiary health science courses. The results suggest that completion of advanced secondary school mathematics, but not physical sciences, is predictive of student achievement. This outcome further supports the need for improved uptake and completion of advanced mathematics in secondary school.
\end{abstract}

Keywords: health science, academic performance, university, mathematics, science, GPA

\section{Introduction}

Healthcare is Australia's leading employer, with approximately $15 \%$ of all individuals employed in the healthcare sector (Australian Healthcare and Hospitals Association, 2017). There remains however, critical shortages of qualified staff in some areas of health service delivery (Australian Healthcare and Hospitals Association, 2017). In recent years there has been a relatively steady increase in the number of positions in tertiary level university programs (Department of Education, Skills and Employment, 2020) to address this workforce deficit. The increasing number of applicants for tertiary education courses come from a diverse demographic background, with varied previous education, personal characteristics and levels academic achievements (Norton, Cherastidtham and Mackey, 2018). Given the surge of enrolments, it is important therefore to investigate predictors of academic achievement, with a focus on fixed and dynamic predictors of academic performance among tertiary students.

Numerous predictors of academic performance have been investigated across a wide range of universities and degree types. The predictive value of demographic markers such as socioeconomic status (Li \& Dockery, 2014), gender (Sheard, 2009), age (Sheard, 2009), employment (Stinebrickner \& Stinebrickner, 2003), and high school performance (Anderton, Evans \& Chivers, 2016; Hoffman \& Lowitzki, 2005; Richardson, Abraham \& Bond, 2012) have been investigated. Of the important unmodifiable variables, gender has been reported as a consistent significant contributor to tertiary academic performance, with females consistently outperforming their male counterparts (Anderton, Evans and Chivers, 2016; Anderton, Hine and Joyce, 2017; Vitali, Blackmore, Mortazavi \& Anderton, 2020). The aforementioned relationship between gender and academic performance is considered to be multifactorial encompassing the heightened desire to please peers (Pomerantz, Alterman \& Saxon, 2002), learning style (Nuzhat, Salem, Hamdan \& Ashour, 2013), approach to feedback and achievement (Roberts, 1991), and influence of social 
capital (Chee, Pino \& Smith, 2005). Pomerantz et al. (2002) demonstrated this trend from as early as primary school with females consistently outperforming males academically in all 4 core subjects (social studies, language arts, mathematics and science). As an extension, a similar trend was observed by Anderton et al. (2016) and Davies, Heyworth, Rosenwax, Carr, \& Rosenberg, (2009), with superior performances from females compared to their male counterparts in tertiary health and science degrees. Taken together, previous and current literature suggest that females have better academic performance, and it is proposed that this effect will also be observed in tertiary health science courses.

The transition from secondary school to tertiary education is particularly stressful, with key factors that may influence overall tertiary academic performance. One factor includes emotional and social competencies, with a strong association between academic success measured by grade point average in the first year as well as dimensions of emotional intelligence including adaptability, intrapersonal and stress management abilities (Parker, Summerfeldt, Hogan \& Majeski, 2004). It should be noted that an individual's emotional and social competencies are dynamic and change over the course of their tertiary education. This adaptability and learning has been reported as a factor linked to subsequent yearly increases in tertiary academic performance (Parker et al., 2004; Vitali et al., 2020). Furthermore, in the transition from secondary school to tertiary education Griff and Matter (2008) and Gultice et al. (2015) identified academic preparation and organisation skills as factors contributing to overall academic success in a tertiary environment. Another factor affecting this transition from high school to the tertiary education environment and indirectly tertiary academic success, is the utilisation of an academic advisor for course selection, exposure to university experience and help with balancing study, work and life issues (Gultice et al., 2015; Steele, 2018).

A traditional entry pathway into Australian university degrees involves the successful completion of Year 12 and obtaining a minimum Australian Tertiary Admission Rank (ATAR) score. This score is calculated from the grades obtained in four or more Stage 2 or Stage 3 high school subjects, with competency in English as the only prerequisite (Joyce, Hine \& Anderton, 2017). Previous research by Mills, Heyworth, Rosenwax, Carr \& Rosenberg (2009) demonstrated that students who engaged well with Science, Technology, Engineering, Mathematic (STEM) subjects throughout high school achieved higher matriculation scores, and then went on to outperform those who did not engage well with STEM in tertiary anatomy and physiology, a core subject in health science degrees (Anderton, Evans \& Chivers, 2016; Gultice et al., 2015). In additional, Green, Brown and Ward (2009) identified an association between subjects studied in high school and success in tertiary health science units. Similar findings more recently were demonstrated by Anderton, Evans and Chivers (2016), identifying high school Human Biology, Physics and Chemistry as significant predictors of academic success in first year tertiary anatomy and physiology. Although the impact of subject selection has been investigated previously, it does not quantify the effect on academic success or whether this effect is carried throughout the degree to graduation. This study aims to investigate the effect of secondary school STEM subjects on academic performance in students studying health science degrees at an Australian University. It is hypothesised that completion of secondary school STEM subjects is associated with academic success in university. To achieve this, this study investigated the relationship between secondary STEM subjects and university academic achievement in a cross-sectional and longitudinal cohort of Australian undergraduate health science students.

\section{Methods}

\subsection{Participants}

Data of first year health and science students enrolling directly from secondary school into a private Australian University between 2012 and 2015 were utilised for this study. In a retrospective study design, only data from students aged 20 or less who entered University using a valid Australian Tertiary Admission Ranking (ATAR) score were considered (Anderton \& Chivers, 2016). Students enrolled full time in Science, Biomedical Science, Exercise and Sports Science, Health and Physical Education, Nursing and Physiotherapy were included. Secondary school data and ATAR were obtained through the Student Admission Office database, with approval granted from the University Human Research and Ethics Committee.

\subsection{Assessment of Socioeconomic Status}

Socioeconomic status is known to contribute to student academic attainment and was therefore included as a possible covariant in the current study. Using socioeconomic indexes for areas (SEIFA), the listed residential postcode of students was categorised according to the 2013 Australian Bureau of Statistics' socioeconomic indexes for areas (ABS, 2016). Postcodes were assigned a value of $1-10$ corresponding to the Western Australian SES percentile for that postcode. For example, high SES suburbs in the top percentile bracket $(90-100)$ were assigned a value of 10 , with the lowest percentile backed $(0-10)$ assigned a value of 1 . 


\subsection{Secondary School Subjects and ATAR}

A traditional entry pathway into Australian university degrees involves the successful completion of Year 12 and obtaining a minimum ATAR score. This score is calculated from the grades obtained in four or more Stage 2 or Stage 3 high school subjects, with competency in English as the only prerequisite (Joyce, Hine \& Anderton, 2017). In the current study, data linking participant secondary school science and mathematics ATAR subjects with university academic performance data were recorded. These secondary school subjects include biology, human biology, chemistry, physics, physical education studies, mathematics 3A3B, mathematics 3C3D and mathematics specialist. Mathematics 3C3D focuses on the use of calculus and statistical analysis, while the mathematics specialist course builds on and deepens the ideas presented in mathematics 3C3D. It is recommended that mathematics 3C 3D is studied in conjunction with specialist mathematics ATAR course. For subsequent analyses, students completing mathematics 3C3D and specialist were combined.

\subsection{University GPA}

The use of Grade Point Average (GPA) is common practice to calculate and report university academic performance and applicable across the majority of studies (Anderton, Hine \& Joyce, 2017). For GPA calculations, student unit results were awarded a 0 (Fail, <50), 1 (Pass, 50-59), 2 (Credit, 60-69), 3 (Distinction, 70-79) or 4 (High Distinction, 80-100) (Joyce, Hine \& Anderton, 2017). The mean GPA at the completion of first year and final year were obtained for participants in the current study.

\subsection{Data Analysis}

Data was described and analysis was conducted using SPSS version 26 (IBM corporation). Naïve differences between high school subject selection and first-year GPA were analysed using a Mann Whitney U test. A significant nominal p-value of <.05 was employed for all statistical tests. For cross sectional analyses, a generalised linear model (GLM) was used to analyse the relationship between secondary school subject selection and first-year GPA, with gender and undergraduate degree type included as covariates. For repeated measures analysis of GPA in a subset of students, generalized linear mixed models (GLMMs) were used to investigate the impact of secondary school subject completion. Akaike information criterion (AIC) was used to compare model fit, where a lower value indicated better model fit. Residual plots were examined for all models and no violations were noted.

\section{Results}

\subsection{Cohort Descriptive Statistics}

The 709 tertiary health science course student cohort comprises 526 females and 363 males (Table 1), with descriptive analysis performed to better understand the cohort in terms of GPA, ATAR, SEIFA (Table 1); as well as chosen degree and high school subject selection (Table 1). To further investigate the effect of high school subject selection on GPA in tertiary health science courses, a subset of the cross-sectional population was followed until completion of their degree. The longitudinal student sample was 458 participants, comprising 363 females and 95 males (Table 1). Descriptive statistics of the 458 tertiary health science course students was performed to better understand the cohort in terms of GPA, ATAR, SEIFA (Table 3); as well as chosen degree and high school subject selection (Table 1). 
Table 1. Descriptive statistics of direct school leaver tertiary health science students enrolled between 2012 and 2015. This includes data for a cross-sectional $(n=709)$ and longitudinal repeated measures $(n=458)$ cohort.

\begin{tabular}{|c|c|c|c|}
\hline \multirow{2}{*}{ Variable } & & \multicolumn{2}{|c|}{ Mean (SD) or n (\%) } \\
\hline & & Cross-sectional & Longitudinal \\
\hline $\mathbf{N}$ & & 709 & 458 \\
\hline \multirow[t]{2}{*}{ Gender } & Male & $183(25.81)$ & $95(20.74)$ \\
\hline & Female & $526(74.19)$ & $363(79.26)$ \\
\hline SEIFA & & $8.07(2.45)$ & $7.95(2.47)$ \\
\hline ATAR & & $82.14(9.86)$ & $82.55(9.44)$ \\
\hline \multirow[t]{6}{*}{ School subject } & Human biology & $317(44.71)$ & $222(48.47)$ \\
\hline & Biology & $45(6.35)$ & $26(5.68)$ \\
\hline & Physical education & $204(28.77)$ & $117(25.55)$ \\
\hline & Math 3C3D & $71(10.01)$ & $49(10.70)$ \\
\hline & Chemistry & $125(17.73)$ & $91(19.87)$ \\
\hline & Physics & $57(8.04)$ & $39(8.52)$ \\
\hline \multirow[t]{2}{*}{ GPA } & First year & $2.09(0.67)$ & $2.20(0.63$ \\
\hline & Final year & - & $2.31(0.55)$ \\
\hline \multirow[t]{6}{*}{ Degree } & Biomedical Science & $80(11.28)$ & $54(11.79)$ \\
\hline & Exercise \& Sports Science & $119(16.78)$ & $82(17.90)$ \\
\hline & $\begin{array}{l}\text { Health \& Physical } \\
\text { Education }\end{array}$ & $72(10.16)$ & $37(8.08)$ \\
\hline & Nursing & $274(38.65)$ & $213(46.51)$ \\
\hline & Physiotherapy & $150(21.16)$ & $71(15.50)$ \\
\hline & Science & $13(1.83)$ & - \\
\hline
\end{tabular}

SEIFA, Socio-Economic Indexes for Areas; ATAR, Australian Tertiary Admissions Rank; GPA, Grade point average

\subsection{Assessment of Secondary School Subjects as Predictors of First Year GPA}

In order to further assess the association between high school subject selection and GPA, generalised linear models (GLM) were constructed to ascertain predictors of GPA. Univariate analysis revealed gender $(p<0.05)$ and degree $(p$ $<0.05)$, but not SEIFA $(p>0.05)$, were associated with GPA. Therefore, models investigating the association of subject completion and GPA controlled for these variables. Completion of Maths 3C3D, Chemistry and PE studies were associated with first year GPA $(p<0.001)$ (Table 2). In models correcting for covariates, completion of Maths 3C3D (padj <0.001), Chemistry (padj <0.001), Physics (padj $=0.032$ ) and PE studies (padj <0.001) resulted in significant differences in GPA. Completion of Maths 3C3D, Chemistry and Physics were all associated with a significantly higher first year GPA, completion of PE studies was associated with a significantly lower first year GPA. There were no significant associations identified between completion of either Human Biology or Biology and GPA in either naïve or corrected regression models (Table 2). 
Table 2. The effect of secondary school subject completion on first year GPA in students enrolled in undergraduate health science degrees. Data presented as mean +/- SD.

\begin{tabular}{lllll}
\hline Subject & \multicolumn{2}{l}{ Completion of subject } & $\begin{array}{l}\text { P value } \\
\text { Naïve comparison }\end{array}$ & $\begin{array}{l}\text { Covariate } \\
\text { corrected }\end{array}$ \\
& Yes & No & & 0.253 \\
\hline Human Biology & $2.1274(0.64)$ & $2.0649(0.72)$ & 0.138 & 0.108 \\
Biology & $1.95(0.66)$ & $2.1022(0.69)$ & 0.214 & $<\mathbf{0 . 0 0 1}$ \\
Mathematics 3C3D & $2.4937(0.72)$ & $2.0482(0.67)$ & $<\mathbf{0 . 0 0 1}$ & $\mathbf{0 . 0 3 2}$ \\
Physics & $2.2063(0.67)$ & $2.0829(0.69)$ & 0.087 & $<\mathbf{0 . 0 0 1}$ \\
Chemistry & $2.3146(0.67)$ & $2.0454(0.69)$ & $<\mathbf{0 . 0 0 1}$ & $<\mathbf{0 . 0 0 1}$ \\
Physical Education & $1.9118(0.637)$ & $2.1660(0.70)$ & $<\mathbf{0 . 0 0 1}$ & \\
\hline
\end{tabular}

4.3 Completion of Math3C3D is a Significant Predictor of GPA over the Course of Health and Science Degrees

In a longitudinal subset of 458 students, the influence of secondary school subject selection on first and final year tertiary GPA was investigated. In this cohort, overall mean GPA in the final year was greater compared to first year $(p<0.001)$. In GLMMs correcting for covariates gender and degree, completion of Maths 3C3D was significantly associated with GPA ( padj $=<0.001$ ). In this subset, students who completed secondary Maths 3C3D achieved a significantly greater GPA in first year ( 0.44 points) that was maintained until final year ( 0.42 points) (Table 3$)$. In contrast, when accounting for repeated measures, corrected GLMMs revealed that completion of Human Biology ( $p$ $=0.288)$, Biology $(p=0.154)$, Physics $(p=0.834)$, Chemistry $(p=0.492)$, and Physical Education Studies $(p=0.075)$, were not associated with GPA (Table 3). However, completion of Physical Education approached statistical significance $(p=0.075)$, despite mean GPA differences in groups being marginal at the completion of study (Table $3)$.

Table 3. Covariate corrected generalised linear mixed models to investigate the effect of secondary school subject on repeated measures GPA

\begin{tabular}{|c|c|c|c|c|c|}
\hline \multirow[t]{2}{*}{ Subject } & \multicolumn{2}{|c|}{ First year GPA } & \multicolumn{2}{|c|}{ Final year GPA } & \multirow{2}{*}{$\begin{array}{l}\text { Corrected } \\
\text { P-value }\end{array}$} \\
\hline & Yes & No & Yes & No & \\
\hline Human Biology & $\begin{array}{l}2.23 \\
(0.61)\end{array}$ & $2.21(0.64)$ & $2.30(0.54)$ & $2.34(0.56)$ & 0.288 \\
\hline Biology & $\begin{array}{l}2.08 \\
(0.58)\end{array}$ & $2.23(0.62)$ & $2.46(0.59)$ & $2.31(0.55)$ & 0.154 \\
\hline Mathematics 3C3D & $\begin{array}{l}2.61 \\
(0.62)\end{array}$ & $2.17(0.61)$ & $2.70(0.53)$ & $2.28(0.53)$ & $<0.001$ \\
\hline Physics & $\begin{array}{l}2.32 \\
(0.58)\end{array}$ & $2.21(0.63)$ & $2.45(0.50)$ & $2.31(0.55)$ & 0.834 \\
\hline Chemistry & $\begin{array}{l}2.40 \\
(0.57)\end{array}$ & $2.18(0.63)$ & $2.31(0.60)$ & $2.33(0.54)$ & 0.492 \\
\hline Physical Education & $\begin{array}{l}2.09 \\
(0.61)\end{array}$ & $2.27(0.62)$ & $2.25(0.52)$ & $2.35(0.56)$ & 0.075 \\
\hline
\end{tabular}

GPA, Grade point average

\section{Discussion}

This study aimed to investigate the influence of secondary school subject selection on academic performance in tertiary health science courses. Our findings showed that completion of Mathematics 3C3D in secondary school was significantly associated with student academic performance in the first year of university health science courses. Moreover, when accounting for repeated measures, after completing this level of Mathematics at secondary school, students demonstrated a significantly higher GPA throughout the course of their degree. The type and level of mathematics studied in secondary school has been reported previously as a determinant of first year university success (Barry \& Chapam, 2007; Joyce, Hines \& Anderton, 2017; Nicholas, Poladian, Mack \& Wilson, 2015), 
however such an association has not been investigated longitudinally, or across multiple health science university degrees. This study explored this effect further and demonstrated that secondary school higher level mathematics continues to significantly impact university academic performance from the start until completion of the degree.

Secondary school mathematics develops the fundamentals of coming to a solution, resolving truths and uncovering errors, which are essential for university education, however only higher-level secondary mathematics is identified as achieving this. What makes higher level secondary school mathematics different to the lower levels is the introduction of calculus into the curriculum (School Curriculum and Standards Authority, 2020). Initially a course in calculus covers functions, later moving to concepts of limits, derivatives and then integrals, and once the fundamentals are mastered it can be used to form mathematic arguments and be applied to most facets of the world around us (Stewart, 2009). These general calculus concepts become significantly advantageous as they can be seen as universally applicable when considering a degree in allied health, as the curriculum covers in part physical and applied sciences. This may be extended further to say that higher level secondary school mathematics encourages higher order thinking skills, allowing students to critically analyse situations, and extend their capacity to use mathematical concepts abstractly in real life situations (Belward et al., 2011). It is therefore clear that undertaking higher level mathematics at secondary school has a significant positive impact on university academic performance in first year health science degrees that carries on throughout the duration of the course.

The completion of secondary school physical sciences has previously been associated with the attainment of a higher ATAR score, and subsequently admission to competitive university programs (Anderton, Hine and Joyce 2017; Manny, Tam, Lipka, \& Yin, 2019). When corrected for covariates, the completion of secondary school Physics was significantly associated with first year GPA. In addition, Physics was not seen as a significant factor when investigated longitudinally with repeated measures across the duration of a degree. Completion of chemistry in secondary school was also significantly associated with performance in first year GPA. However, in the subset of student performance studied longitudinally, it did not appear as a significant factor. These findings are consistent with Anderton, Hines and Joyce (2017), who stated "students who completed physical sciences (Chemistry \& Physics) were shown to have significantly higher GPAs than those students who did not complete these subjects; and similar previous literature by Schwartz, Sadler, Sonnert and Tai (2008) as well as Manny et al. (2019).

The impact of physical science on tertiary health science academic performance is believed to be due to a combination of the methods used to teach these subjects (Schwartz et al., 2008) and the content itself (Vitali et al. 2020). For example, Chemistry and Physics subjects are considered to be taught in 'depth' with the aim of students developing advanced understanding of key and specific concepts, whereas other science subjects such as Biology, are taught in 'breadth' which provides a wide, general understanding of concepts. In keeping with this idea, it has been suggested that broader coverage of course content leads to negative university performance, when compared to more focussed subjects taught within a discipline that encourages the development of a deeper understanding of the structure of the discipline (Schwartz et al., 2008). Completion of both Physics and Chemistry significantly impact positively on first year academic performance in tertiary health science courses independently, however from the findings of this study this effect does not appear to continue across the duration of the degree for either subject.

Undertaking Physical Education as a secondary school subject was associated with a significantly lower first year GPA. While this trend appeared to be present across the duration of the degree, negatively impacting university academic performance, the effect did not reach statistical significance. Physical Education is seen as a secondary subject that covers a wide variety of broad topic areas, rather than developing a deeper understanding of key and specific concepts. As such, this may coincide with significantly poorer tertiary health science academic performance, which aligns with the findings presented in this study and previous literature (Kirk, 2014).

The findings of this current study are strengthened by a recent review by Rasberry et al. (2011), who investigated the effect of physical education studies and academic achievement reported in ten studies. These authors conclude that there is no clear relationship between physical education studies and academic performance. Secondary Physical Education studies significantly impacts negatively on $1^{\text {st }}$ year academic performance in tertiary health science courses; and although this effect is not significant throughout the duration of the degree the trend appears to still exist. This finding may be an important factor to consider in future studies as more than a quarter of all students in this study completed secondary Physical Education prior to university.

There were some limitations associated with this research project that require acknowledgement. Firstly, the sample cohort consist of tertiary health science students from a single private Australian university, therefore the findings may have limited generalisability to other institutions. Secondly, the authors were limited by data availability and could only look at whether students had completed particular ATAR secondary school subjects, rather than the 
specific scores obtained in each subject. However, this study only reported results for secondary school leavers, excluding other students who are mature aged or entered via alternative methods in the same degree.

\section{Conclusions}

The hypothesis that completion of secondary school STEM subjects is associated with academic achievement in undergraduate health science degrees was supported in part. The completion of secondary school physics, chemistry, and Maths 3C3D was associated with higher first year GPA, but when considering longitudinal analysis, only completion of Maths 3C3D was a significant determinant of overall GPA. Additionally, Physical Education demonstrated a trend towards a negative effect on tertiary health science academic performance. This study has particular importance within the Australian tertiary system in relation to STEM, enabling university faculties to better understand the academic challenges that some students face in their transition to chosen STEM University courses. The present study examined the influence of secondary school subjects in isolation, however in most cases, in particular with secondary mathematics, students are also undertaking at least one science subject. It should therefore be noted there may be some crossover effect, as all secondary subjects will form the final ATAR score, with potential to influence university academic performance. While universally available, support services in both secondary school and university can become increasingly customized to these student vulnerabilities or targeted to those students who have not completed mathematics, in order to address these deficits. It is anticipated that customising or targeting services to students most likely to falter will improve student's transition to university, retention and ultimately graduation.

\section{References}

Anderton, R., Evans, T., \& Chivers, P. (2016). Predicting academic success of health science students for first year anatomy and physiology. International Journal of Higher Education, 5(1), 250-260. https://doi.org/10.5430/ijhe.v5n1p250

Anderton, R., Hine, G., \& Joyce, C. (2017). Secondary School Mathematics and Science Matters: Academic Performance for Secondary Students Transitioning into University Allied Health and Science Courses. International Journal of Innervation in Science and Mathematics Education, 25(1), 34-47.

Australian Bureau of Statistics [ABS]. (2016). Census of Population and Housing: Socio-Economic Indexes for Areas (SEIFA), $\quad$ Australia, $2013 . \quad$ Retrieved from http://stat.data.abs.gov.au/Index.aspx?DataSetCode=SEIFA_SSC\#

Australian Healthcare and Hospitals Association. (2017). Health Workforce. Retrieved from https://ahha.asn.au/sites/default/files/docs/policy-issue/ahha_position_statement_health_workforce_3.pdf

Bacon, D. R., \& Bean, B. (2006). GPA in research studies: An invaluable but neglected opportunity. Journal of Marketing Education, 28(1), 35-42. https://doi.org/10.1177/0273475305284638

Barry, S. I., \& Chapman, J. (2007). Predicting university performance. ANZIAM Journal, 49, 36-50. https://doi.org/10.21914/anziamj.v49i0.304

Belward, S., Matthews, K. E., Thompson, K. V., Pelaez, N. J., Coady, C., Adams, P., Simbag, V., \& Rylands, L. (2011). Applying mathematical thinking: The role of mathematicians and scientists in equipping the new generation scientist. In J. Hannah \& M. Thomas (Eds.), Proceedings of Volcanic Delta 2011: The Eighth Southern Hemisphere Conference on Teaching and Learning Undergraduate Mathematics and Statistics, 12-21.

Chee, K., Pino, N., \& Smith, W. (2005). Gender differences in the academic ethic and academic achievement. College Student Journal, 39(3), 604-618

Davies, C., Heyworth, J., Rosenwax, L., Carr, S., \& Rosenberg, M. (2009). Factors associated with the academic success of first year Health Science students. Advances in Health Science Education, 14, 205-217. https://doi.org/10.1007/s10459-008-9103-9

Department of Education, Skills and Employment. (2020). Higher Education Statistics: Student Data. Retrieved from https://www.education.gov.au/student-data

Green, R., Brown, E., \& Ward, A. (2009). Secondary school science predictors of academic performance in university bioscience subjects. Anat Sci Educ, 2(3), 113-118. https://doi.org/10.1002/ase.82

Griff, E. R., \& Matter, S. F. (2008). Early identification of at-risk students using a personal response system. British Journal of Educational Technology, 39(6), 1124-1130. https://doi.org/10.1111/j.1467-8535.2007.00806.x 
Gultice, A., Witham, A., \& Kallmeyer, R. (2015). Are your students ready for anatomy and physiology? Developing tools to identify students at risk for failure. Advances in physiology education, 39(2), 108-115. https://doi.org/10.1152/advan.00112.2014

Hoffman, J., \& Lowitzki, K. (2005). Predicting college success with high school grades and test scores: limitations for minority students. The Review of Higher Education, 8(4). https://doi.org/10.1353/rhe.2005.0042

Joyce, C., Hine, G., \& Anderton, R. (2017). The association between secondary mathematics and first year university performance in health sciences. Issues in Educational Research, 27(4), 770-782.

Kirk, D. (2014). Physical Education and Curriculum Study (Routledge Revivals): A Critical Introduction. Routledge. https://doi.org/10.4324/9781315849935

Li, I., \& Dockery, M. (2014). Socio-economic status of schools and university academic performance: implications for Australia's higher education expansion. National Centre for Student Equity in Higher Education, Perth, W.A.: Curtin University.

Manny, A., Tam, H., Lipka, R., \& Yin, Z. (2019). Data Analysis: The impact of senior secondary study choices on success at university. University Admission Centre (NSW \& ACT).

Mills, C., Heyworth, J., Rosenwax, L., Carr, S., \& Rosenberg, M. (2009). Factors associated with the academic success of first year health science students. Adv Health Sci Educ Theory Pract, 14(2), 205-217. https://doi.org/10.1007/s10459-008-9103-9

Nicholas, J., Poladian, L., Mack, J., \& Wilson, R. (2015). Mathematics preparation for university: entry, pathways and impact on performance in first year science and mathematics subjects. International Journal of Innovation in Science and Mathematics Education (formerly CAL-laborate International), 23(1).

Norton, A., Cherastidtham, I., \& Mackey, W. (2018). Mapping Australian higher education 2018. GrattanInstitute (Carlton, VIC: September, 2018).

Nuzhat, A., Salem, R., Hamdan, N., \& Ashour, N. (2013). Gender differences in learning styles and academic performance of medical students in Saudi Arabia. Medical teacher, 35, 78-82. https://doi.org/10.3109/0142159X.2013.765545

Parker, J. D., Summerfeldt, L. J., Hogan, M. J., \& Majeski, S. A. (2004). Emotional intelligence and academic success: Examining the transition from high school to university. Personality and individual differences, 36(1), 163-172. https://doi.org/10.1016/S0191-8869(03)00076-X

Pomerantz, E., Alterman, E., \& Saxon, J. (2002). Making the Grade but Feeling Distressed: Gender Differences in Academic Performance and Internal Distress. Journal of Educational Psychology, 94(2), 396-404. https://doi.org/10.1037/0022-0663.94.2.396

Rasberry, C., Lee, S., Robin, L., Laris, B., Russell, L., Coyle, K., \& Nihiser, A. (2011). The association between school-based physical activity, including physical education and academic performance: A systematic review of the literature. Preventative Medicine, 52, S10-S20. https://doi.org/10.1016/j.ypmed.2011.01.027

Richardson, M., Abraham, C., \& Bond, R. (2012). Psychological correlates of university students' academic performance: A systematic review and meta-analysis. Psychological Bulletin, 138(2), 353-387. https://doi.org/10.1037/a0026838

Roberts, T. (1991). Gender and the influence of evaluations on self-assessment in achievement settings. Psychological Bulletin, 109, 297-308. https://doi.org/10.1037/0033-2909.109.2.297

School Curriculum and Standards Authority. (2020). Mathematics Methods. Retrieved from https://senior-secondary.scsa.wa.edu.au/syllabus-and-support-materials/mathematics/mathematics-methods

Schwartz, M.C., Sadler, P.M., Sonnert, G., \& Tai, R.H. (2008). Depth versus breadth: How content coverage in high school science courses relates to later success in college science coursework. Science Education, 2-29. https://doi.org/10.1002/sce.20328

Sheard, M. (2009). Hardiness commitment, gender, and age differentiate university academic performance. British Journal of Educational Psychology, 79(1), 189-204. https://doi.org/10.1348/000709908X304406

Steele, G. E. (2018). Student Success: Academic Advising, Student Learning Data, and Technology. New Directions for Higher Education, 2018(184), 59-68. https://doi.org/10.1002/he.20303

Stewart, J. (2009). Calculus: Concepts and contexts. Cengage Learning. 
Stinebrickner, R., \& Stinebrickner, T. (2003). Working during school and academic performance. Journal of Labor Economics, 21(2), 473-491. https://doi.org/10.1086/345565

Vitali, J., Blackmore, C., Mortazavi, S., \& Anderton, R. (2020). Tertiary Anatomy and Physiology, A Barrier for Student Success. International Journal of Higher Education, 9(2), 289-296. https://doi.org/10.5430/ijhe.v9n2p289

\section{Copyrights}

Copyright for this article is retained by the author(s), with first publication rights granted to the journal.

This is an open-access article distributed under the terms and conditions of the Creative Commons Attribution license (http://creativecommons.org/licenses/by/4.0/). 